\title{
Acute pancreatitis as presenting complication of Acute myeloid leukemia (A rare case and Literature Review)
}

\author{
Dr. Manju ${ }^{1}$, Dr. Dhiraj Kapoor ${ }^{2}$, Dr. V.D. Dogra ${ }^{3}$, Dr. Gaveshna gargi ${ }^{4}$, Dr. Harita ${ }^{5}$, \\ Dr. Kavita sharad ${ }^{6}$, Dr. Gopal Singh,$\star ;, 7$
}

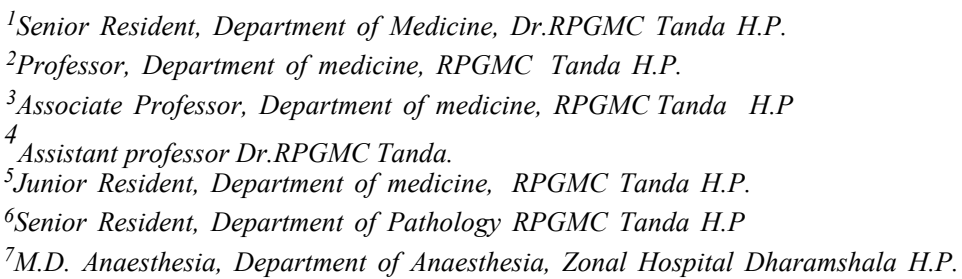

DDOI: https://doi.org/10.15520/jcmro.v2i12.238

Accepted 07-12-2019; Received 10-11-2019; Publish Online 09-12-2019

Reviewed By: Dr.

REKIKU FIKRE

ABEBE

Department:

Reviewer/CMRO

\begin{abstract}
Pancreatitis is a rare manifestation of Acute myeloid leukaemia (AML) arising during or after onset of course of disease. It can be first and only manifestation of AML. AML is a type of blood cancer. Characterized by clonal proliferation of abnormal myeloid precursors and altered normal hematopoiesis. The world Health organization (WHO) classification retains the diagnostic threshold the infiltration of the bone marrow by more than $20 \%$ of non-lymphoidblasts.

We reported a case of AML discovered in a 36-year-old female admitted with chief complaints of pain epigastrium. On Clinical examination she was conscious co-operated well oriented. Blood pressure: 110/70 mmHg, abdominal examination revealed epigastric tenderness, no organomegaly. CVS, Respiratory system and neurological examination were within normal limit. On investigation amylase was 856/ UL and Lipase 690 U/L, USG abdomen suggestive of acute pancreatitis. Complete haemogram was done as base line investigation which revealed leukocytosis $1.30 \mathrm{lac} / \mathrm{microlit}, \mathrm{Hb}-8$ gm, platelets 32 tuousands only. The blood smear revealed the presence of circulating Blast-28, Atypical cells $32 \%$, myelocytes $7 \%$ and metamyelocytes $6 \%$ and reduced platelets. The bone marrow aspiration and biopsy suggestive of AML. Myeloperoxidase staining was positive. The patient was diagnosed as Acute pancreatitis and managed symptomatically. After improvement she was referred to PGIMER Chandigarh for further management of AML.
\end{abstract}

Key words: Acute myeloid leukemia (AML)-Acute pancreatitis (AP)-Lymphoblastic leukemia (LAL).

\section{INTRODUCTION:}

Acute myeloid leukemia (AML) is a heterogeneous clonal disorder characterized by immature myeloid cell proliferation and bone marrow failure. Over the years there have been several different classification systems for AML based on etiology, morphology, immune-phenotype and genetics. In the 1970s, AML was classified according to the FrenchAmerican-British classification system using mainly mor-

\footnotetext{
* Corresponding author

† Email: drgopalsingh07@gmail.com
}

phology and immune-phenotype/cytochemical criteria to define eight major AML subtypes (FAB M0 to M7).

The incidence of AML in adults is 5 to $8 / 100,000$ per year in Europe, it increases with age, especially after 50 years. The mortality rate is 4 to $6 / 1,00,000 /-$ per year. The median age of diagnosis is 65 years.

The diagnosis of AML requires examination of blood and medullary smears by trained cytologist. Cytogenetic study of the marrow (karyotype and in situ hybridization in FISH fluorescence) and a study in molecular biology (gene rearrangements resulting from abnormalities chromosome). We 


\section{Acute pancreatitis as presenting complication of Acute myeloid leukemia (A rare case and Literature Review)

diagnosed a case of AML in a 36 year old patient, revealed by acute pancreatitis, and we discuss it in the light of data from the literature.

\section{CASE REPORT:}

36 years old women admitted at Medicine department, rural tertiary care institution Govt. Medical College Kangra at Tanda with complaints epigastric pain with vomiting for 4-5 days with no other significant history. On clinical examination found a dehydrated patient, blood pressure: 110/70 $\mathrm{mmHg}$, abdominal examination revealed epigastric tenderness, no organomegaly. CVS, Respiratory system within normal limit and The neurological examination was normal eliminating a possibility of neuron-meningeal blastic infiltration.

The biochemical assessment showed lipase at $690 \mathrm{IU} / 1$, Blood Sugar; $116 \mathrm{mg} / \mathrm{dl}$, urea: $26 \mathrm{~m} \mathrm{~g} / \mathrm{dl}$, Creatinine: $0.82 \mathrm{mg}$ Calcium: $8 \mathrm{mg} \%$ Phosphorus: $3.2 \mathrm{~m} / \mathrm{dl}$; Uric acid: $5.5 \mathrm{mg} / \mathrm{d}$, CRP: $114 \mathrm{mg} /$, LDH: $325 \mathrm{U} / \mathrm{L}$, Total proteins: $6.3 \mathrm{~g} / \mathrm{dl}$ and Albumin $3.0 \mathrm{gm} / \mathrm{dl}$. Serology for HBV; HBC; CMV and HIV are negative; Syphilitic serology is also negative. Serology was negative for rickettetial and leptospirosis. The hemogramm showed: anemia at $8 \mathrm{~g} / \mathrm{dl}$, MVC $81 \mathrm{fl}$, Leukocytes $1.30 \mathrm{lac} / \mathrm{ul}$ and Platelats at 32,000/ul. Total bilirubin $1.65 \mathrm{mg} / \mathrm{dl}$, SGOT/SGPT 298/223 IU/L, Alkaline phosphate $220 \mathrm{IU} / \mathrm{L}$. The medullogram showed the presence of $59 \%$ of undifferentiated blasts and myeloblasts Figure 1 with the positivity of myeloperoxidase activity. The blood smear Figure 2 revealed the presence of circulating blasts estimated at $36 \%$. (The immunophenotyping and flow cytometry study could not be carried out due to lack of facility. Abdominal ultrasound is suggestive of aute panreatitis Figure 3. Abdominal CT scan (performed after 48 hours of onset of symptomatology) also s/o acute pancreatitis.

In our patient acute pancreatitis (AP) was classified moderate according to the Ranson score. At the end of this assessment, the diagnosis of AP associated with AML was retained. The patient was managed with $\mathrm{I} / \mathrm{V}$ fluids ,antibiotics and other symptomatic treatment is being given. Due to lack of further investigation like flow cytometry, immunophenotyping and for further management patient was referred to higher institution, PGIMER Chandigarh.
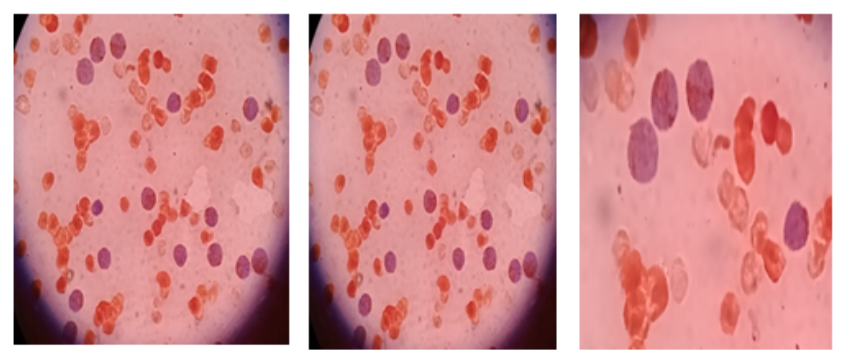

Figure 1. Bonemarrow staining showing undiffernitated blast clells and myeloblasts, Of mediumsize, a rounded or oval nucleus, With the presence of nucleoli, fine chromatinand more or less

basophilic cytoplasm strewn with azurophilic granulations.

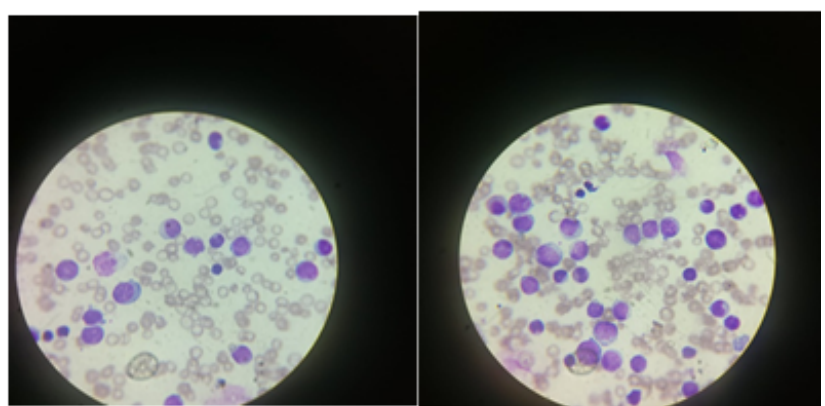

Figure 2. Blood smear showingmedium sized blasts, nucleus rounded to oval, basophilic cytoplasm withpresence of some azurophilic granulations

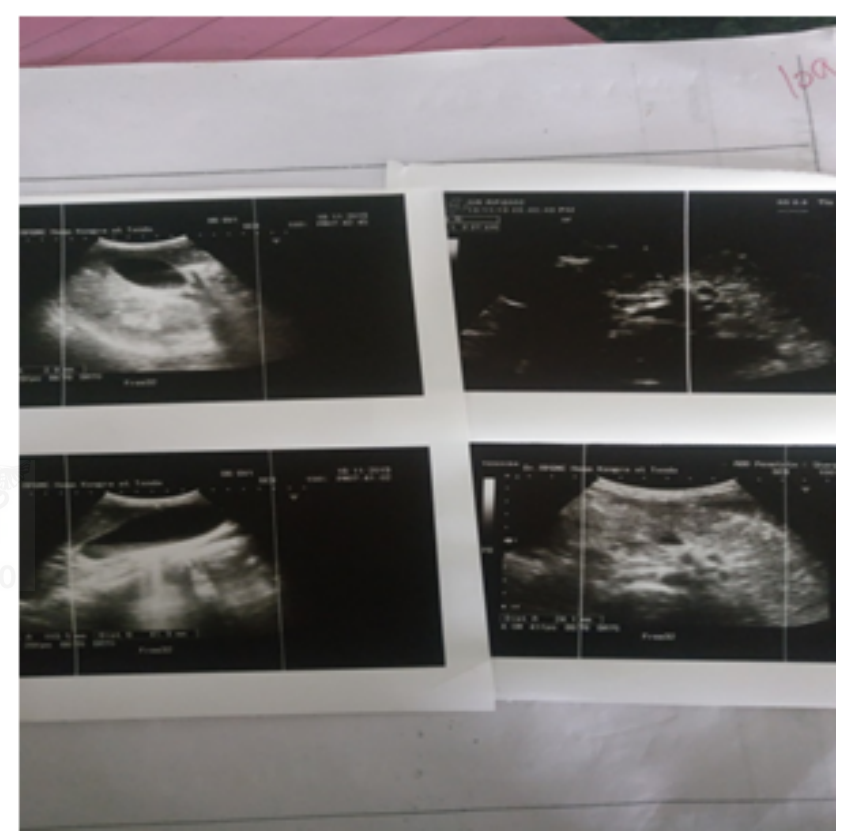

Figure 3. USGAbdomen showing bulky pancreas, Heterogenousechotexture of head, body anddistal part. Gall bladder overdistended with normal wall. No evidence ofpericholecytic fluid.

Acute pancreatitis due to AML is very rare. Main causes of Acute pancreatitis are [21] biliary calculi (approximately $40 \%$ of AP), Chronic and significant alcoholism (approximately 40\%) .Rare Causes are malignant or benin tumors of pancreas, Postoperative, Endoscopic retrograde cholangiopancreatography. Exceptional causes hypertirglyceridemia (>10 mmo1/1). Hypercalcemia regardless of cause, Drugs, Infectious (viral, bacterial, mycotic, parasitic) Autoimmune Pancreas divisum and idiopathic. In our case no such causes are found.

\section{DISCUSSION:}

Acute pancreatitis is a common complication of gall bladder stones or chronic alcoholism and hypercalcemia .Cause of hypercalcemia may be multiple like primary or sec- 
ondary lympho-proliferative syndromes. Pancreatic infiltration with leukemic cells is a rare manifestation of acute lymphoblastic leukemia (LAL) [1]. Acute pancreatitis in LAL is either due to hypercalcemia or post chemotherapy, but direct damage to the pancrease by leukemic cells is rarely observed. [2, 3]. But in our case all these causes were ruled out. The diagnosis of acute pancreatitis is based on the asso-ciation of typical abdominal pain with an elevation of lipase and amylase above 3 times normal. Image were done for the diagnosis and severity (classification of Balthazard).

The incidence of AML with recurrent cytogenetic abnormalities decrease with age $[4,5]$. The translocation $\mathrm{t}(8 ; 21)$ is present in about $5 \%$ to $10 \%$ of all AML cases and $10 \%$ to $22 \%$ of AML 2 cases [6-8]. This is a translocation affecting chromosomes 8 and 21 . In $75 \%$ of cases, there are other associated chromosomal abnormalities, the most common being the loss of a sexual chromosome, the interstitial deletion of the long arm of chromosome 9, and trisomy 8 [9].

Several studies have concluded that t $(8 ; 21)$ tends to form at the myeloid cells [10] our patient, the diagnosis of acute pancreatitis associated with acute myeloid leukemia, but the severity of acute pancreatitis classified according to the Ranson Score.

But the question remains: is there a link between these two pathologies? In the rare cases of association between acute leukemia and acute pancreatitis (AP), it is either an acute lymphoblastic leukemia leading to a hypercalcaemia at the origin of the AP, which is not the case of our patient because serum calcium was within normal limit. Other causes like iatrogenic pancreatitis, post-drug pancreatitis or post-chemoth Serapy based on Cytarabine, or Lasparaginses [11] are also not present in our case. By interrogation; the lithiastic etiology was ruled out. Computer tomography scan of the abdomen revealed acute pancreatitis, no obstructive lesion.

Two causes are like to explain the etilogical origin of acute pancreatitis: a pancreatic infiltration by the leukemic cells, a rare but possible etiology, or an idiopathic origin.

\section{CONCLUSION:}

Acute pancreatitis is a severe pathology due to its complications, and its association with acute myeloid leukemia has rarely been reported as site of leukemia. Extrramedullary myeloid tumor in AML is associated with crisis or leukemic transformation complications. Clinicians should entertain pancreatic extremedullaey AML when pancreatic enlargement develops during or after onset of AML.

\section{REFERENCES}

1. Mori, A., Kikuchi, Y., S., Watanabe, J., Shinozaki, M, \& Eguchi, M. (2003). Acute pancreatitis induced by diffuse pancreatic invasion of adult T-cell leukemia/lymphoma cells. Dig Dis Sci 2003; 48:1979-83.

2. Wlazlowski, M., Celinska, W., Maciejka-Kapuscinska, L., Ploszynska, A., \& Idezak, E. (1994). Acute pancreatitis in children with acute lymphoblastic leukemia treated with Lasparaginase. Pol Tyg Lek 1994; 49.296-7.
3. Mantakadis, E., Anagnostatou, N. Smymaki, P., Spanaki, AM. Papavasiliou, ES., Briassoulis, G., et al. (2005) Life-threatening hypercalcemia complicated by pancreatitis in a child with acute lymphoblastic leukemia, J PediatrHematolOncol 2005; 27.288-92.

4. Bacher, U., Kern, W., Schnittger, S., Hiddemann, W., Haferlach, T/. \&Schoch, C. (2005) "Population-based agespecific incidences of cytogenetic subgroups of acute myeloid leukemia," Haematologica, vol.90, no. 11, pp. 1502-1510, 2005 5. Bruserud, O., Hovland, R.Wergeland, L., Huang, T.S., \& Gjertsen, B.T (2003) "Flt3-mediated signaling in human acute myelogenous leukemia (AML) blasts; a functional characterization of the effects of Flt-3 ligand in AML cell populations with and without genetic Flt 3 abnormalities; "Haematologica, vol. 88, no.4, pp.416-428-2003.

6. Arber D.A., Stein, A.S. Carter, N.H. Ikle, D.Forman, S.J \& Slovak, M.L. (2003) "Prognostic impact of acute myeloid leukemia classification: importance of detection of recurring cytogenetic abnormaltiies and multilineage dysplasia on survival," American Journal of Clinical Pathology, vol. 199, no.5 pp.672-680-2003.

7. Klaus, M. Haferlach. T, Schnitter, S. Kern, W. Hiddemann, W., \& Schoch, C. (2004) nreatography Hypertriglyceridemia $(>10 \quad \mathrm{mmol} / 1)$ Exceptional causes Hypercalcemia regardless of cause Drugs (chronology +++ ) Infectious (viral, bacterial, mycotic, parasitic).

8. Frage, S.S., Archer, K.J, Mrozek, K., Vardiman J.W., Caroll A.J., Pettenati M.J, et al. (2002) Isolated trisomy of chromosomes 8, 11, 13 and 21 is an adverse prognostic factor in adults with de novo acute myeloid leukemia; results from Cancer and Leukaemia Group B 8461. International Journal of Oncology 2002 Nov; 21 (5): 1041 R 51.

9. Group Francais de Cytogenetique Hematologique. Acute myelogenousleukaemia with an $(8 ; 21)$ translocation. A report of 148 cases from the Groupefrancia de cytogenetiquehematologique. Cancer GFenetics and cytogenetics. 1990’ 44:169-179

10. Manvelyan, M., Kempf, P., Weise, A. et al., "Preferred colocalization of chromosome 8 and 21 in myeloid bone marrow cells detected by three dimensional molecular cytogenetics,' International Journal of Molecular Medicine, vol. 24, no.3, pp. 335-341, 2009

11. Touaoussa, A., Elhmadi, K., E1 Youssin, H., Eddou, H. \& Amrani Hassani, M. (2015) Leucemie aigue myelomonocytaire a eosinophiles revelee par une pancreatite aigue, The Pan African Medical Journal. 2015' 20: 112. Doi: 10.11604/ pamj.2015 20.112.6024. 